\title{
Male and female bottlenose dolphins Tursiops spp. have different strategies to avoid interactions with tour boats in Doubtful Sound, New Zealand
}

\author{
David Lusseau ${ }^{1,2, *}$ \\ ${ }^{1}$ University of Otago, Department of Zoology, PO Box 56, Dunedin, New Zealand \\ ${ }^{2}$ Present address: University of Aberdeen, Lighthouse Field Station, George St., Cromarty IV11 8YJ, Scotland
}

\begin{abstract}
I assessed the short-term reactions of bottlenose dolphins Tursiops spp. to interactions with tour boats, and their long-term implications. Vertical avoidance of boats, showed by an increase in time spent underwater, is a typical response in cetaceans, and has been likened to predator avoidance strategies. This study looked at the variation in diving pattern of bottlenose dolphins in Doubtful Sound, New Zealand, in relation to boat interactions. An observing vessel was used to collect the data. A regressive approach showed that this vessel did not have a significant effect on the diving pattern of the dolphins. The analysis would have allowed the detection of a small difference $(6.35 \mathrm{~s})$ in dive interval (percentage of variance, PV $=0.05$ ) with high certainty (power $=0.86$ ). Dolphins avoided tour boats vertically by increasing their mean diving interval. Dolphins started to react before boats were in visual contact. An information theoretic approach indicated that the behaviour of the boat was the predominant factor affecting the diving interval. Males and females responded differently to interactions with boats. Males started to avoid boats as soon as they were present, while females switched to a vertical avoidance strategy only when interactions became intrusive. This difference in avoidance strategy may be related to the different metabolic regime of the sexes. Males would be more likely to meet the cost of vertical avoidance of boats because of their greater energy stores. Females vertically avoid boats, an energetically expensive exercise for them, only when the risk incurred by this interaction is high.
\end{abstract}

KEY WORDS: Bottlenose dolphin · Tourism · Impact · Avoidance strategy · Respiration

\section{INTRODUCTION}

Watching whales and dolphins (cetaceans) for tourism purposes is a booming industry (Hoyt 2001). This tourism sector exceeded the US $\$ 1$ billion mark in worldwide indirect expenditures in 1998 (Hoyt 2001). An increase in interest is leading to increased boat traffic around cetaceans, which can have detrimental effects (Duffus \& Dearden 1990).

Cetaceans seem to have various strategies to avoid interactions with boats. They do not try to avoid all interactions, yet if these interactions become too lengthy (Bejder et al. 1999), intrusive (Williams et al. 2002), or unpredictable (Nowacek et al. 2001), cetaceans will try to avoid them. The species studied have shown various horizontal and vertical strategies for evasion. These tactics are very similar to techniques used to elude predators (Howland 1974, Weihs \& Webb 1984). Cetaceans can change their movement pattern to be more elusive, i.e. to a more sinuous and less predictable movement (Baker \& Herman 1989, Nowacek et al. 2001, Williams et al. 2002). They can also increase their swimming speed (Baker \& Herman 1989, Blane \& Jaakson 1995, Nowacek et al. 2001, Williams et al. 2002). Various species of cetaceans have also been observed vertically avoiding boats by increasing the amount of time they spent underwater (Baker \& Herman 1989, Blane \& Jaakson 1995, Janik \& Thompson 1996, Nowacek et al. 2001, Williams et al. 2002). Not all species utilise vertical avoidance in a similar fashion. Responses tend to 
change with the boat movements (Nowacek et al. 2001), the number of boats present (Kruse 1991, Barr 1996), or the distance at which boats approach (Williams et al. 2002), and males and females can display different strategies (Bauer \& Herman 1986, Williams et al. 2002). It therefore appears that interactions with boats are perceived differently, or have different costs for different species and sexes. This variation in response can help us understand the exact nature of the stress factors associated with boat interactions, and its related cost to the animals (Moberg 2000).

Vertical avoidance strategies may be directly related to the physiology of the animals, therefore providing a way to infer interaction costs. Observing the surfacing pattern of cetaceans is an easy way to detect changes in the homeostasis of individuals. Respiration rate is directly related to the metabolic rate of bottlenose dolphins; the higher the metabolic rate is, the more an individual needs to breathe (Yazdi et al. 1999). Other respiration parameters, such as surfacing intervals, are directly related to respiration rate (number of minutes between 2 breaths vs number of breaths $\mathrm{min}^{-1}$ ) and therefore metabolic rate, and can easily be recorded in the field. During vertical avoidance, the animal has to utilise oxygen stores to deal with this decrease in breath intake. In the worst case it will have an oxygen debt that it must restore after boat-interaction avoidance. In both cases this variation in oxygen intake involves extra energy expenditure. Observing surfacing patterns therefore is a first step that helps infer the energetic cost inherent to interactions with boats. It could also help to define whether there is a threshold at which dolphins shift from vertical avoidance to more expensive avoidance strategies, such as changing their behavioural state (Lusseau in press) or avoiding an area entirely. This threshold should be directly related to the energetic cost of vertical avoidance.

I observed the diving pattern of bottlenose dolphins in Doubtful Sound, Fiordland, New Zealand, and its variation during interactions with tour boats. A small population of ca. 65 bottlenose dolphins resides yearround in Doubtful Sound (Williams et al. 1993). This population is a key natural resource for the local tourism industry, which is currently expanding (Lusseau 2002). Because of the pressure to increase dolphin-boat interactions in this area, it is necessary to understand the costs associated with these interactions in order to determine the limits that can be sustained by the dolphins.

\section{MATERIALS AND METHODS}

Field techniques. From December 1999 to February 2002 I conducted systematic surveys in Doubtful Sound $\left(45^{\circ} 15^{\prime} \mathrm{S}, 167^{\circ} \mathrm{E}\right)$ in RV 'Wilma Jane', a $4.8 \mathrm{~m}$ aluminium boat powered with a 50HP 4-stroke outboard engine (the 4-stroke engine was chosen for its reduced noise and fume emissions). I followed the same survey route every day until a group of dolphins was encountered. The route allowed for a complete survey of the fjord, and sampling effort was evenly distributed. Effort was evenly distributed across seasons (summer: December to February, autumn: March to May, winter: June to August, spring: September to November). Once a group was found I stayed with that focal group until it was lost or until weather conditions deteriorated to the point where it was no longer possible to continue.

I recorded surfacing times (New Zealand Standard Time, using a Psion ${ }^{\circledR}$ palmtop computer) of focal individuals when following focal groups for $1 \mathrm{~h}$ at a time. The sampling was thus limited to minimise observer errors due to fatigue. The dataset was downloaded every night onto a laptop computer.

In addition to surfacing times, I recorded the behavioural state of the focal group every $15 \mathrm{~min}$ and classified them into 5 states (see Lusseau in press for detailed definitions): travelling (TR), resting (REST), milling (MI), diving (DIVE) and socialising (SO). Diving most likely represents the 'feeding'/'foraging' categories in other studies (Shane 1990). The gender of the focal animal was known from observations made between 1995 and 2002. The gender of photo-identified individuals was assessed by direct observation of the genital slit using an underwater camera. Both the absence/presence of mammary slits and the distance between the genital and anal slits permitted to sex the animals. I recorded boat presence along with the type of boat and whether the vessel violated the Marine Mammal Protection Regulations (MMPR; New Zealand Government 1992). These regulations established by the New Zealand Government provide guidelines on how to interact with dolphins in order to minimise potential negative effects. Boat interactions violating the MMPR regulations were considered intrusive because they impeded the movement of the group of dolphins. If a vessel was within $400 \mathrm{~m}$ of the focal group it was defined as interacting with the dolphins. Distances between tour boats and dolphins were measured using a Bushnell Yardage Pro ${ }^{\circledR}$ Compact 600 range finder, and were estimated with a measured precision of 1 to $5 \mathrm{~m}$. I defined the $400 \mathrm{~m}$ limit thanks to a preliminary study which showed that dolphins tended to break off from their group to bow-ride a vessel if the vessel was within $400 \mathrm{~m}$ of the group (author's unpubl. data).

Analysis. Samples were blocked both by boat presence and behavioural state, and a mean dive interval was calculated for each sample. Dive intervals were defined as the time elapsed between 2 surfacings of the focal animal, e.g. the time between 2 breaths. These mean dive intervals were subsequently used in 
analyses instead of the samples of raw dive intervals, which are dependent time series, to avoid pseudoreplication (Hurlbert 1984). Mean dive intervals were normalised via log-transform. In addition 'before' and 'after' samples were blocked for each boat interaction, corresponding to 10 min before and after interactions. It was estimated that dolphins would be in acoustic contact with vessels at least $10 \mathrm{~min}$ before and after they interacted with them. This 10 min margin corresponded roughly to vessels being within $6 \mathrm{~km}$ from the dolphins, because it would take roughly $10 \mathrm{~min}$ for a vessel travelling at 20 knots to home on a pod of dolphins $6 \mathrm{~km}$ away. This assumed $6 \mathrm{~km}$ zone of audibility was deduced from preliminary work on the acoustic characteristics of boats present in Doubtful Sound (O. J. Boisseau, S. M. Dawson \& D. Lusseau unpubl. data).

The length of the sample can bias the mean dive interval for this sample. For example Kriete (1995, cited in Williams et al. 2002) showed that for killer whales, samples shorter than $1000 \mathrm{~s}$ tended to bias estimates of surfacing rates. To assess the potential correlation, partial correlations were calculated between the sampling period and dive interval. As the length of the sampling period increases, it is expected that its correlation to the mean dive interval of the sample will decrease until it reaches a non-significant level. I calculated this non-significant threshold for the present dataset and discarded samples shorter than this threshold (Williams et al. 2002).

Effects of the research vessel. Land-based observations could not be carried out in Doubtful Sound because of the remoteness and topography of the fjord. I assessed the effect of the research vessel using a regressive technique widely applied in impact assessment studies in which true controls are not possible (Morrison et al. 2001). I computed 3 levels of 'observation intensity' and examined the dependence of dive intervals to these levels: (1) vessel following the focal group at close range (within $50 \mathrm{~m}$ ); (2) vessel following the focal group from afar (between 100 and $200 \mathrm{~m}$ ); (3) vessels drifting engine off (at least $100 \mathrm{~m}$ away from the dolphins).

The 50 to $100 \mathrm{~m}$ zone was purposefully avoided to ensure a clear separation between the close and far categories.

To assess the effects of the research vessel on the dolphins, I fitted generalised linear models (GLMs) to control samples (samples without boats other than the research vessel). For this and subsequent analyses I used SPSS 9.0. I selected the Type III sums of squares to calculate the GLMs, also known as Yates' weighted squares-of-means, so that the order in which variables were entered did not affect the estimation of the variance they explained (SPSS manual 1999). The effects of season, sex, behavioural state and the movements of the research vessel, as well as their interactions, were included in these models. I used $\eta^{2}$ to estimate the \% variance explained by each parameter (Murphy \& Myors 1998). It is calculated as the ratio of effect variance to total variance. A post-hoc power analysis was then carried out to calculate the minimum detectable effect for each parameter if effects had a small contribution to the total variance. A $5 \%$ of variance explained was considered as a small contribution (Murphy \& Myors 1998). To find the model providing the most information about the data I calculated an Akaike Information Criterion (AIC) for each model. AIC estimates the amount of information a model explains from its residual sums of squares (RSS, related to the amount of the variance left unexplained) and by penalising models for the number of parameters used (Burnham \& Anderson 1998). Therefore the more parameters a model has, the more likely it is to reduce RSS, but a simpler model will be preferred to a more complex one, unless it explains a lot more variability:

$$
\mathrm{AIC}=n \times \ln \left(\frac{\mathrm{RSS}}{n}\right)+2 k
$$

where $k$ is the number of parameters and $n$ the sample size. If the AIC difference between 2 models is $\geq 4$ then the model minimising AIC has considerably more support than the other models (Burnham \& Anderson 1998). If this difference is greater than 10 the other models can be considered to have no support (Burnham \& Anderson 1998). The effects of the research vessel were determined to be negligible if the best model(s) did not include the movements of the observing vessel as an explanatory variable.

Effects of interactions with other boats. A similar approach was undertaken to assess the effects of (nonresearch) boat interactions on the diving pattern of dolphins. GLMs were determined for several parameters and the best model was selected using AIC. First, 3 models, all taking into consideration dolphin parameters, were compared to assess the effect of boat presence. The following boat variables were considered: (1) boat present versus boat absent; (2) BAC I design (boat present, boat absent, before interaction, and after interaction).

Second, I tried to determine what feature of boat interactions (boat type vs boat movement) had the most effect on the diving pattern of the dolphins. I compared 4 models: (1) boat present versus boat absent; (2) powerboat versus kayak versus no boat; (3) no boat versus no violation versus 1 violation of the MMPR versus more than 1 violation.

The following categories are applied hereafter: 'Sex' is the gender of the focal dolphin; 'research vessel' is the behaviour of the research vessel; 'without' samples are samples with only research vessel present; 'boats' are all boat types other than the research vessel. 
Table 1. Tursiops spp. Number of dive interval samples by sex, behavioural state and season. TR: travelling; REST: resting; MI: milling; DIVE: diving; SO: socialising

\begin{tabular}{|llcccc|}
\hline State & Sex & Autumn & Winter & Spring & Summer \\
\hline TR & Male & 60 & 28 & 48 & 31 \\
& Female & 30 & 28 & 66 & 33 \\
REST & Male & 23 & 15 & 9 & 12 \\
& Female & 15 & 4 & 14 & 6 \\
MI & Male & 5 & 4 & 7 & 8 \\
& Female & 9 & 3 & 14 & 4 \\
DIVE & Male & 40 & 40 & 11 & 18 \\
& Female & 19 & 20 & 10 & 14 \\
SO & Male & 18 & 10 & 12 & 11 \\
& Female & 9 & 12 & 10 & 10 \\
\hline
\end{tabular}

\section{RESULTS}

\section{Data collected}

During the study period I spent $137 \mathrm{~d}(879.2 \mathrm{~h})$ of sampling effort and $133 \mathrm{~d}(716.5 \mathrm{~h})$ following dolphins. Dolphins interacted with boats for $10 \%$ of this time. A total of 16005 dive intervals were recorded, corresponding to 941 samples. Samples of up to $300 \mathrm{~s}$ in length had mean dive intervals correlated with the length of the sampling period. These short samples were therefore discarded (remaining samples: Pearson's correlation $=0.005, \mathrm{p}=0.892, \mathrm{n}=742$ ). A total of 742 samples were kept (Table 1) of which 126 were recorded in the presence of boats (Table 2 ).

\section{Effects of the research vessel}

For 248 control samples the position of the research vessel in relation to dolphins was known (134 'close', 70 'far', and 44 'stopped'). There were not enough samples to fit a 4 -way GL model (sex $\times$ behavioural state $\times$

Table 2. Tursiops spp. Number of dive interval samples by sex, boat presence and season. Without: samples where only research vessel was present; With: tour boats present; Before: $10 \mathrm{~min}$ before dolphin-boat interactions; After: $10 \mathrm{~min}$ after dolphin-boat interactions

\begin{tabular}{|llcccc|}
\hline State & Sex & Autumn & Winter & Spring & Summer \\
\hline Without & Male & 57 & 79 & 51 & 50 \\
& Female & 55 & 49 & 63 & 37 \\
With & Male & 38 & 7 & 16 & 11 \\
& Female & 10 & 8 & 20 & 16 \\
Before & Male & 25 & 7 & 8 & 10 \\
& Female & 8 & 6 & 14 & 5 \\
After & Male & 28 & 4 & 12 & 9 \\
& Female & 9 & 4 & 17 & 9 \\
\hline
\end{tabular}

season $\times$ state of research vessel), so four 3 -way models were fitted to the data: (1) sex $\times$ behavioural state $x$ state of the research vessel; (2) sex $\times$ season $\times$ state of the research vessel; (3) season $x$ behavioural state $\times$ state of the research vessel; (4) season $\times$ sex $\times$ behavioural state.

In all models the effect of the research vessel was not significant $\left(F_{2,(193,218,225)}<1, \alpha>0.5, \eta^{2}<0.005\right)$. Models could have detected a small difference in variance (0.05) due to the presence of the research vessel with a high level of probability ( $\beta=0.86$ ). Given the data, I had an $86 \%$ chance of detecting a $6.35 \mathrm{~s}$ difference in mean dive interval (back-transformed minimum detectable difference) between the different categories of exposure to the research vessel.

AIC favoured the model that did not consider any effect of the research vessel as best explaining the dataset (Table 3). There was an AIC difference of 8.1 between the best model and the next one, indicating no support for the latter (Burnham \& Anderson 1998).

The analyses indicate that the presence of the research vessel had no significant effect on the dolphins' dive intervals. Dive intervals varied depending on season and the sex of the focal individual (Fig. 1, Table 4). Males had significantly longer dive intervals than females $(45.9 \mathrm{~s}, \mathrm{n}=139, \mathrm{SD}=1.39$ vs $39.9 \mathrm{~s}, \mathrm{n}=$ $109, \mathrm{SD}=1.34$ ) and dive intervals tended to be longer in autumn and summer compared to spring and winter $(51.4 \mathrm{~s}, \mathrm{n}=41, \mathrm{SD}=1.43$ in autumn vs $39.9 \mathrm{~s}, \mathrm{n}=68$, $\mathrm{SD}=1.46$ in winter).

From this analysis it is apparent that sex and season affect mean dive interval. The behavioural state of dolphins does not seem to play an important role. Low sample size made it impossible to assess the interactions between these 3 parameters and boat parameters. Therefore only sex and season were considered subsequently in the analyses.

\section{Boat presence}

Three models were compared to examine the effect of boat presence (Table 5). All these models consid-

Table 3. Tursiops spp. Model selection using Akaike Information Criteria (AIC). A low AIC value indicates a better fit of the model to the data. RV: research vessel; RSS: residual sums of squares; $\mathrm{n}$ : sample size; $\mathrm{k}$ : number of parameters in the model. $x$ describes a fully saturated model including all variables

\begin{tabular}{|lcccc|}
\hline Model & RSS & $\mathrm{n}$ & $\mathrm{k}$ & AIC \\
\hline Sex $\times$ state $\times$ RV & 4.12 & 248 & 8 & -1000.0 \\
Sex $\times$ season $\times$ RV & 3.81 & 248 & 8 & -1019.3 \\
Season $\times$ state $\times$ RV & 3.74 & 248 & 8 & -1024.0 \\
Season $\times$ sex $\times$ state & 3.62 & 248 & 8 & -1032.1 \\
\hline
\end{tabular}




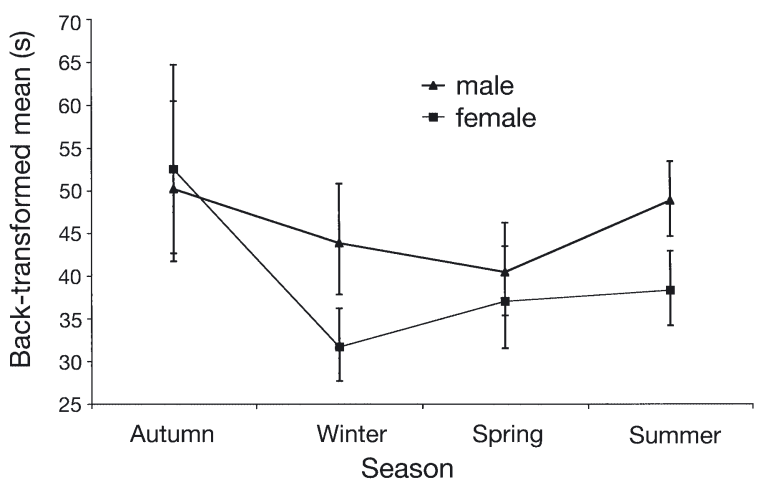

Fig. 1. Tursiops spp. Back-transformed predicted mean dive intervals from a General Linear Model (GLM) depending on the sex of the focal animal and the season. Error bars are 95\% CIs

ered the effect of sex and season on the data. The model that considered before and after interaction periods best fitted the data (Table 5). There was an AIC difference of 17, with the next best model showing that the other models were not supported by the data.

Boat presence $\left(F_{3,711}=4.25, \alpha=0.005, \eta^{2}=0.018\right)$ and $\operatorname{sex}\left(F_{1,711}=17.82, \alpha<0.001, \eta^{2}=0.024\right)$ were the only factors with a significant effect on mean dive intervals. The effect of boat presence was not as important as the effect of sex $\left(\eta^{2}=0.018\right.$ vs 0.024$)$. The dives were significantly longer during interactions with boats than without boats present (Bonferroni post-hoc test, $\alpha<$ 0.01). Before and after periods were not significantly different from periods without boats (Bonferroni posthoc test, $\alpha>0.05)$, nor were they different from periods with boats (Bonferroni post-hoc test, $\alpha>0.05$ ). They seemed to be transitory states between 'with' and 'without' periods (Fig. 2).

Table 4. Tursiops spp. Results of the Generalised Linear Model (GLM) considering sex, state, season and their interactions as explanatory factors. For each parameter the table displays degrees of freedom (df), significance of the F-ratio $(\alpha)$, $\%$ variance explained $\left(\eta^{2}\right)$, power $(\beta)$ and minimum detectable difference (mdd). $\beta$ gives power for a small effect ( $P V=0.05$, Murphy \& Myors 1998); mdd is back-transformed around the mean (in seconds), for a small effect $(\mathrm{PV}=0.05)$

\begin{tabular}{|lrcccc|}
\hline Effect & df & $\alpha$ & $\eta^{2}$ & $\beta$ & mdd \\
\hline Season & 3 & 0.001 & 0.078 & & 6.74 \\
Sex & 1 & 0.017 & 0.027 & & 6.04 \\
State & 4 & 0.112 & 0.035 & 0.75 & 6.25 \\
Season $\times$ sex & 3 & 0.227 & 0.021 & 0.80 & 6.06 \\
Season $\times$ state & 12 & 0.687 & 0.042 & 0.53 & 4.98 \\
Sex $\times$ state & 4 & 0.686 & 0.011 & 0.75 & 6.07 \\
Season $\times$ sex $\times$ state & 11 & 0.782 & 0.033 & 0.55 & 7.62 \\
& & & & & \\
\hline
\end{tabular}

Table 5. Tursiops spp. Model selection using Akaike Information Criteria (AIC). A low AIC value indicates a better fit of the model to the data. P/A: presence/absence of boats, B/A: 10 min before and after dolphin-boat interactions. RSS: residual sums of squares; $\mathrm{n}$ : sample size; $\mathrm{k}$ : number of parameters in the model. $\times$ describes a fully saturated model including all variables

\begin{tabular}{|lcccc|}
\hline Model & RSS & $\mathrm{n}$ & $\mathrm{k}$ & $\mathrm{AIC}$ \\
\hline Sex $\times$ season & 16.40 & 742 & 4 & -2820.4 \\
Sex $\times$ season $\times$ P/A & 16.05 & 742 & 8 & -2828.7 \\
Sex $\times$ season $\times(\mathrm{P} / \mathrm{A}, \mathrm{B} / \mathrm{A})$ & 15.68 & 742 & 8 & -2845.7 \\
\hline
\end{tabular}

\section{Features of boat interactions}

The 'violation' model fitted the data best (Table 6). The next best model had an AIC difference of 16.4 with the violation model, indicating that violations of the MMPR influenced the diving pattern of the dolphins far more than the type of boat interacting with them. Moreover, this model explained more variation in the dataset than the others (Table 6). There was a significant effect of violation $\left(F_{3,537}=4.73, \alpha=0.003, \eta^{2}=\right.$ $0.026)$ and gender $\left(F_{1,537}=11.52, \alpha=0.001, \eta^{2}=0.021\right)$ in this model. There were no significant interactions. These 2 main factors explained an equal proportion of the variance ( 2 to $3 \%$ ) in the dataset.

\section{Differences between males and females}

There was no interaction between sex and violation, however the effects of MMPR violations were different depending on the sex of the focal animal. In the

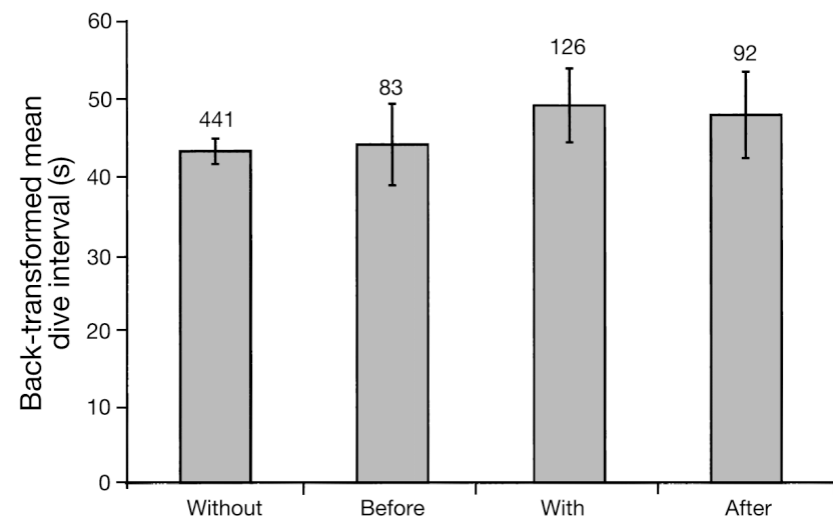

Fig. 2. Tursiops spp. Mean dive interval in each state of boat presence. Error bars are 95\% CIs. Sample size is included above each bar. Without: only research vessel present; Before: 10 min before dolphin-boat interactions; With: tour boats present; After: 10 min after dolphin-boat interactions 
Table 6. Tursiops spp. Model selection using Akaike Information Criteria (AIC). A low AIC value indicates a better fit of the model to the data. P/A: presence/absence of boats, type: boat type (kayak vs powerboat), violation: number of violations of the Marine Mammal Protection Regulations (MMPR) performed during interactions $(0,1$, or $>1)$. RSS: residual sums of squares; n: sample size; k: number of parameters in the model; $\eta^{2}$ : proportion of the dataset variance explained by the model. $\times$ describes a fully saturated model including all variables

\begin{tabular}{|lccccc|}
\hline Model & RSS & $\mathrm{n}$ & $\mathrm{k}$ & AIC & $\eta^{2}$ \\
\hline Sex $\times$ season & 12.32 & 567 & 4 & -2163.3 & 0.066 \\
Sex $\times$ season $\times$ P/A & 11.94 & 567 & 8 & -2172.8 & 0.057 \\
Sex $\times$ season $\times$ type & 11.73 & 567 & 8 & -2182.8 & 0.071 \\
Sex $\times$ season $\times$ violation & 11.40 & 567 & 8 & -2199.2 & 0.122 \\
\hline
\end{tabular}

case of females, violations had a significant impact on the dive interval. Disruptive interactions significantly increased the dive interval of female dolphins, compared to interactions in which boats did not break the law, and samples without boats (Bonferroni post-hoc test on female samples only, $\alpha<0.01$ ). Violations had an additive effect (Fig. 3). The more violations were committed during an interaction, the greater the increase in dive interval for females. By contrast, males were not as affected by violations (Bonferroni post-hoc test on male samples only). Their dive interval did not vary significantly depending on the presence of violations (Fig. 3) or on the number of violations committed (Fig. 3). It varied significantly with the presence of boats (Fig. 3). The effect on females was important, with an $18.6 \%$ increase in dive interval when 1 violation occurred, and $37.1 \%$ increase for more than 1 violation (Fig. 3).

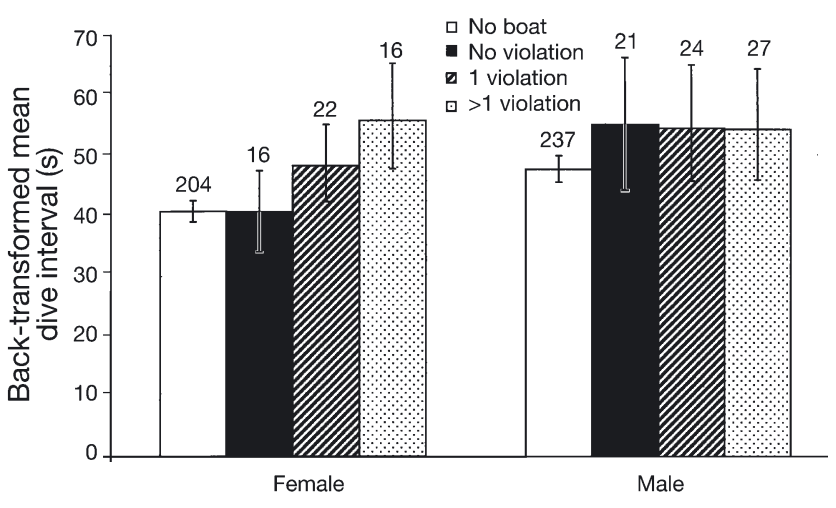

Fig. 3. Tursiops spp. Effects of committing 1 or more violations of the Marine Mammal Protection Regulations (MMPR) during interactions with female and male dolphins on the mean dive intervals. Error bars are 95\% CIs. Sample size is included above each bar

\section{DISCUSSION}

Boat interactions influenced the diving pattern of bottlenose dolphins in Doubtful Sound. Dolphins displayed typical vertical avoidance during interactions with boats. Dolphins increased their dive intervals before interactions, suggesting that they were aware of approaching boats. The effect of interactions decayed over the minutes after interactions, the zone of influence of boat interactions seems to go beyond the physical exposure to vessel and most likely matches the zone where dolphins are in acoustic contact with vessels.

It is possible for a powerboat not to affect the respiratory pattern of these dolphins. The research vessel, to which dolphins have been exposed for $8 \mathrm{yr}$, did not seem to affect their diving behaviour significantly. This vessel has spent in excess of $2400 \mathrm{~h}$ with dolphin groups in Doubtful Sound. During that time the MMPR guidelines were always strictly observed and interactions were terminated at any sign of avoidance. This behaviour may have meant that the dolphins did not associate the presence of the research vessel with any potential danger.

The majority of the interactions observed in Doubtful Sound violated the MMPR (70.6\% of the 126 samples). These violations were the factor that most strongly influenced the diving pattern of dolphins when boats interacted with them. Because of the repetitive intrusiveness of tour boat interactions, dolphins may have started to regard them as a threat. This could explain why dolphins started altering their diving pattern before the vessels were in their close vicinity. It also shows that the zone of behavioural influence of boats is much greater than previously thought. My definition of proximity, based on visual cues, is clearly different from the dolphin's definition (which I assume is based primarily on acoustic cues). It is important to note that the type of vessel interacting with the dolphins did not matter as much as the manner in which this boat moved around the dolphins. A kayak and an $18 \mathrm{~m}$ catamaran could trigger a similar avoidance response from dolphins if they were not respecting the Marine Mammal Protection Regulations. The difference in responses to the exposure of the observing vessel and to the exposure of tour boats shows that the current code of conduct can minimise the impact of interactions with dolphins.

\section{Different strategies for different metabolic regimes}

Females had a shorter average dive interval than males did. They therefore breathed more often than males did, potentially relating to higher energetic demands (Yadzi et al. 1999) and therefore a higher 
overall metabolic rate. However, these results need to be treated cautiously because of the low percentage of the variance explained by the models. It also seems that colder months (winter and spring) were more energetically demanding for the animals (Williams et al. 2001). A decrease in temperature would mean more energy being required to maintain body temperature. Even if animals were to increase the thickness of their blubber layer to cope with lower temperature, it would result in both an increase in energy requirements and the activation of additional biological functions (i.e. an increase in metabolic rate). Bottlenose dolphins have some degree of sexual size dimorphism, i.e. larger males (Read et al. 1993), which could explain an intersexual difference in metabolic rate. Mothers were not considered as a class separate from other females and this could also explain the discrepancy in energy requirements between males and females. There were not enough samples to assess differences between females and mothers because I did not have enough samples of females unaccompanied by calves. Different energetic demands between sexes may explain the difference observed in response to boat approaches. Mothers have to provide energy to their calves during pregnancy and for 1 to $2 \mathrm{yr}$ after birth. Following a predator-avoidance strategy model, it is possible that the observed extra energetic demand on females prevents them from vertically avoiding a perceived threat (Howland 1974, Weihs \& Webb 1984). They would therefore only increase their dive interval when necessary, i.e. when the threat is real (e.g. risk of injuries for example) during intrusive interactions. Males would have more energy available to avoid any potential problem via short-term vertical avoidance. It is also possible that females are reluctant to use vertical avoidance when accompanied by a calf because of the limited diving capacity of their offspring. However, 3 mo old calves were observed accompanying their mothers on dives lasting more than $3 \mathrm{~min}$. So it is unlikely that the diving capacity of calves inhibits a vertical avoidance response from their mothers. Assessing differences in response between mothers and unaccompanied females would permit to separate the effects of energetic demands inherent to the presence of calves, from the potential extra costs of females' metabolic requirements.

Other studies of respiration patterns in bottlenose dolphins show no discrepancy between sexes e.g. Nowacek et al. (2001), whose study took place in shallow, warm waters and therefore diving costs and functions may differ. However, similar differences were observed in killer whales living in another cold temperate fjord system (Williams et al. 2002). Females did not change their dive interval when approached by boats, while males did. In Doubtful Sound the presence of a boat was sufficient to increase the mean dive interval of males. For females the behaviour of the vessels needed to become intrusive and less predictable to affect them. Unfortunately these results cannot be compared to other studies because the level of violations of the MMPR observed in Doubtful Sound is unmatched in other locations (Lusseau 2002). However this difference in response can help us infer that boat interactions with dolphins have a biologically significant cost to these animals.

\section{Management recommendations}

Bottlenose dolphins in Doubtful Sound live in mixedsex schools (Lusseau et al. 2003). It is therefore not possible to provide different management strategies for the different responses observed by the 2 sexes because both sexes will almost always be encountered in a dolphin school. Immediate steps need to be taken to significantly reduce the number of violations of the MMPR via both education and enforcement (Lusseau 2002). The energy requirements of dolphins seem to increase during winter. Since a biological cost of boat interactions is apparent, at least for females, management should seek to avoid interactions during times when dolphins are already stressed (Moberg 2000) by environmental factors, such as cold temperature or decreased prey availability. Unless regulation violation rates are reduced, dolphin-watching activities should be banned during winter months when environmental stresses are high. Finally the biological cost of boat interactions on females is of prime concern for the population's numerical stability. The role of females in population growth is important and the cost of stressors on the success of pregnancies can be devastating (Moberg 2000). There is an apparent risk of decreased calf survival rate, as well as increased stillbirths. These risks warrant immediate actions.

Acknowledgements. This study was funded by the New Zealand Department of Conservation, Southland Conservancy. I am grateful for the constant support that Drs. E. Slooten and S. M. Dawson contributed throughout this study. This manuscript was improved by the comments of 4 anonymous referees. I would also like to thank the New Zealand Whale and Dolphin Trust, University of Otago, University of Otago Bridging Grant scheme, and Real Journeys, that contributed additional financial assistance and technical support in the field.

\section{LITERATURE CITED}

Baker CS, Herman LM (1989) Behavioural responses of summering humpback whales to vessel traffic: experimental and opportunistic observations. Final Report to the National Park Service, Alaska Regional Office, Anchorage 
Barr K (1996) Impacts of tourist vessels on the behaviour of dusky dolphins (Lagenorhynchus obscurus) at Kaikoura. MSc thesis, University of Otago, Dunedin

Bauer GB, Herman LM (1986) Effects of vessel traffic on the behaviour of humpback whales in Hawaii. Report to the National Marine Fisheries Services, Honolulu

Bejder L, Dawson SM, Harraway JA (1999) Responses by Hector's dolphins to boats and swimmers in Porpoise Bay, New Zealand. Mar Mamm Sci 15(3):738-750

Blane JM, Jaakson R (1995) The impact of ecotourism boats on the Saint Lawrence beluga whales. Environ Conserv 21(3):267-269

Burnham KP, Anderson DR (1998) Model selection and inference: a practical information-theoretic approach. Springer-Verlag, New York

Duffus DA, Dearden P (1990) Non-consumptive wildlifeoriented recreation: a conceptual framework. Biol Conserv 53:213-231

Howland HC (1974) Optimal strategies for predator avoidance: the relative importance of speed and manoeuvrability. J Theor Biol 47:333-350

Hoyt E (2001) Whale watching 2001: worldwide tourism numbers, expenditures and expanding socioeconomic benefits. Report to IFAW and UNEP, London

Hurlbert SH (1984) Pseudoreplication and the design of ecological field experiments. Ecol Monogr 54:187-211

Janik VM, Thompson PM (1996) Changes in surfacing patterns of bottlenose dolphins in response to boat traffic. Mar Mamm Sci 12:597-602

Kriete B (1995) Bioenergetics in the killer whale, Orcinus orca. PhD thesis, University of British Columbia, Vancouver

Kruse S (1991) The interactions between killer whales and boats in Johnstone Strait, BC. In: Norris KS, Pryor K (eds) Dolphin societies: discoveries and puzzles. University of California Press, California, p 149-159

Lusseau D (2002) The state of the scenic cruise industry in Doubtful Sound in relation to a key natural resource: bottlenose dolphins. Proc Ecotourism, Wilderness and Mountain Tourism Conference, August 27-29 2002. University of Otago, Department of Tourism, Dunedin

Lusseau D (2003) The effects of tour boats on the behavior of bottlenose dolphins (Tursiops spp.): using Maskov chains to model anthropogenic impacts. Conserv Biol

Editorial responsibility: Otto Kinne (Editor),

Oldendorf/Luhe, Germany
Lusseau D, Schneider K, Boisseau OJ, Haase P, Slooten E, Dawson SM (2003) The bottlenose dolphin community of Doubtful Sound features a large proportion of long-lasting associations. Can geographic isolation explain this uniqueness? Behav Ecol Sociobiol DOI 10.1007/500265-0030651.y

Moberg GP (2000) Biological response to stress: implications for animal welfare. In: Moberg GP, Mench JA (eds) The biology of animal stress. CAB International, Cambridge, p 1-21

Morrison ML, Block WM, Strickland MD, Kendall WL (2001) Wildlife study design. Springer-Verlag, New York

Murphy KR, Myors B (1998) Statistical power analysis. Lawrence Erlbaum, London

New Zealand Government (1992) Marine Mammal Protection Regulations 1992. Wellington, New Zealand Goverment Printer

Nowacek SM, Wells RS, Solow AR (2001) Short-term effects of boat traffic on bottlenose dolphins, Tursiops truncatus, in Sarasota Bay, Florida. Mar Mamm Sci 17(4):673-688

Read AJ, Wells RS, Hohn AA, Scott MD (1993) Patterns of growth in wild bottlenose dolphins, Tursiops truncatus. J Zool 231:107-123

Shane SH (1990) Behaviour and ecology of the bottlenose dolphin at Sanibel Island, Florida. In: Leatherwood S, Reeves RR (eds) The bottlenose dolphin. Academic Press, New York, p 245-266

Weihs D, Webb PW (1984) Optimal avoidance and evasion tactics in predator-prey interactions. J Theor Biol 106: 189-206

Williams JA, Dawson SM, Slooten E (1993) The abundance and distribution of bottlenosed dolphins (Tursiops truncatus) in Doubtful Sound, New Zealand. Can J Zool 71: 2080-2088

Williams R, Trites AW, Bain D (2002) Behavioural responses of killer whales (Orcinus orca) to whale-watching boats: opportunistic observations and experimental approaches. J Zool 256:255-270

Williams TM, Haun J, Davis RW, Fuiman LA, Kohin S (2001) A killer appetite: metabolic consequences of carnivory in marine mammals. Comp Biochem Physiol A 129:785-796

Yazdi P, Kilian A, Culik BM (1999) Energy expenditure of swimming bottlenose dolphins (Tursiops truncatus). Mar Biol 134:601-607

Submitted: December 6, 2002; Accepted: May 6, 2003

Proofs received from author(s): July 18, 2003 